\title{
RECONSTRUCCIÓN VIRTUAL DEL PRESIDIO DE SAN PEDRO DEL GALLO EN EL CAMINO REAL DE TIERRA ADENTRO, MÉXICO ${ }^{(*)}$
}

\author{
VIRTUAL RECONSTRUCTION OF THE PRESIDIO OF SAN PEDRO DEL GALLO IN THE CAMINO REAL \\ DE TIERRA ADENTRO, MEXICO
}

\author{
ROBERTO CARRILLO ACOSTA ${ }^{[\star]}$ \\ Universidad Autónoma de Zacatecas (México) \\ robertohistory@hotmail.com \\ Fecha de recepción: 03 de agosto de 2018 \\ Fecha de aprobación: 17 de setiembre de 2018
}

\begin{abstract}
RESUMEN
Las investigaciones sobre fortificaciones y arquitectura militar son muy escasas, así como los esfuerzos por interpretar, reconstruir o recrear estos espacios, en el caso de haberse perdido la evidencia física de su existencia. La intención del presente trabajo es precisamente dar a conocer qué es un presidio, los espacios que lo componían y las actividades que allí se realizaban, a través de una reconstrucción histórica, pero también virtual, esta última llevada a cabo mediante levantamientos arquitectónicos. Con ello, se espera lograr la puesta en valor de estas edificaciones y quizá, en un futuro, elevar una propuesta para que las fortificaciones del norte del Camino Real de Tierra Adentro sean declaradas como patrimonio cultural, en la categoría de patrimonio militar o fortificado.
\end{abstract}

\section{PALABRAS CLAVE}

Fortificaciones; Camino Real de Tierra Adentro; Presidio del Gallo

\begin{abstract}
Research on fortifications and military architecture is quite scarce, efforts to interpret and reconstruct these spaces, in the cases where physical evidence of their existence have been lost, are so as well. The purpose of this paper is precisely to show what is a presidio, as well as the spaces and activities that constituted said structure. This is achieved through a historical and a virtual reconstruction, where the latter is carried out through an architectural survey. Hopefully, it will revalue these edifices and perhaps, in the future, we will put forth a proposal that the fortifications of the Camino Real north of Tierra Adentro be declared cultural heritage, in the category of military or fortified heritage.
\end{abstract}

\section{KEYWORDS}

Fortifications; Camino Real de Tierra Adentro; Presidio of San Pedro del Gallo

\footnotetext{
${ }^{*}$ ) El presente escrito forma parte de la investigación realizada por Carrillo Acosta para obtener el grado de doctor en Historia por la Universidad Autónoma de Zacatecas (UAZ), 2009-2012, asesorada por J. Enciso Contreras; y de sus proyectos titulados Transformación del Paisaje en el Camino Real de Tierra Adentro: Fortificaciones y Patrimonio en el Septentrión, siglos XVII y XVIII, y Apropiación, Uso y Transformación de los Caminos Militares en el Norte de la Nueva España, durante los siglos XVII y XVIII, ambos realizados en la UAZ, como parte del Programa para el Desarrollo Profesional Docente, en el marco del grupo de investigación Historia e Interpretación del Patrimonio (HIPAT).

$\left({ }^{* *}\right)$ Licenciado, maestro y doctor en Historia por la UAZ, fue responsable de la Biblioteca especializada en Antropología e Historia Camino Real de Tierra Adentro, resguardada por el Instituto Nacional de Antropología e Historia de Zacatecas, durante el periodo 2001-2009. Es docente investigador de la Licenciatura en Historia de la UAZ desde 2014 a la fecha. Ha realizado diversas publicaciones y conferencias en torno a dicho tema.
} 
devenir Vol. 6, Nº11, ENERO - JUNIO 2019, PP. 9-24 - ESTUDIOS I ISSN 2312-7562 I E-ISSN 2616-4949

UnIVERSIDAD NACIONAL DE INGENIERÍA, LIMA

doi: https://doi.org/10.21754/devenir.v6i11.631

El presente trabajo es resultado de la labor de investigación realizada desde el año 2017 a la fecha, la cual ha incluido la búsqueda y el rastreo de información general sobre las fortificaciones establecidas en el norte del México durante los siglos XVII y XVIII, y específicamente sobre aquellas que se construyeron próximas al tendido de la ruta histórica conocida como Camino Real de Tierra Adentro. Así, la atención también se centró en el tramo que abarca los actuales estados de Durango y Chihuahua, que corresponden precisamente a la parte norte de la ruta en la jurisdicción de México. En dicho tramo se instalaron los presidios de El Pasaje, San Pedro del Gallo, Mapimí, San Miguel de Cerro Gordo y San Francisco de Conchos. La investigación se realizó en dos etapas: la primera corresponde a la investigación documental, llevada a cabo durante el año 2017; la segunda implicó la realización de investigación de campo en los sitios identificados como presidios, lo cual incluyó encuestas, entrevistas y observación en el sitio, además de un levantamiento fotográfico. Tras concentrar todo el material reunido durante ambas etapas y hacer el respectivo análisis, se procedió a elaborar la descripción arquitectónica de dichas fortificaciones para después realizar la reconstrucción virtual de las mismas. Hasta el momento, se han culminado las reconstrucciones del presidio de Cerro Gordo y de San Pedro del Gallo: este último es el tema del presente trabajo.

Es común en el norte de México que haya poca o nula evidencia física de los presidios que se establecieron, no solo en las cercanías del tendido del Camino Real', sino en todo su territorio. Sucede que cuando una región era pacificada dejaba de tener sentido que permaneciera allí un puesto de control militar. Mientras cada sitio geográfico se iba poblando, las tropas emigraban a terrenos más cercanos a la frontera norte, para brindar seguridad. Si bien algunos soldados se quedaban en las poblaciones surgidas alrededor del presidio, la mayoría seguía con su labor militar en uno diferente. Por ello, incluso desde su construcción, algunos presidios estaban destinados a perecer: en algunos casos, su construcción fue improvisada o no se llevó a cabo con la idea de permanencia, pero la mayoría de veces estos se modificaron para levantar nuevos edificios, que fueron transformando los espacios del presidio en espacios vecinales, civiles. De esta manera, en la actualidad estas construcciones presidiales han quedado fraccionadas, y sus espacios dispersos entre casas habitación, haciendas, iglesias o edificios de gobierno, mientras que otros quedaron expuestos a la intemperie o simplemente desaparecieron.

El objetivo de la presente investigación es recuperar no solo la memoria histórica, sino también la arquitectónica, la cual ahora es posible señalar como intangible. Es importante brindar a las poblaciones que surgieron de un presidio la posibilidad de vincularse con su identidad de origen, pero esta labor debe trascender el ejercicio de la palabra y la imaginación de cómo eran estas fortificaciones; es necesario hacerlas palpables y visibles, con tanta fidelidad como sea posible. Es mediante la reconstrucción virtual de los presidios que se puede comenzar a satisfacer ese deseo de pertenencia; además, de ello pueden derivar muchas actividades más: la posibilidad de una reconstrucción física, la revitalización del espacio como un centro de interpretación o un museo, e incluso lograr la declaratoria como patrimonio militar.

La reconstrucción pretendida tendrá inicialmente carácter virtual, a manera de maqueta, pero se considera que posteriormente se pueda realizar también de manera física, llevarse a la práctica. Para llevar a cabo la reconstrucción virtual, se siguieron tres pasos metodológicos. En primer lugar, se recuperó la producción historiográfica respecto de la región y del tema en cuestión, entre la que destacan la tesis Presidio y Población Indígena en la Nueva Vizcaya, Siglos XVII y XVIII, de Arturo Guevara Sánchez; y los libros El Presidio, de Max Leon Moorhead; y El Presidio en México en el Siglo XVI, de Luis Arnal Simón, que contienen dibujos o croquis de los presidios. El siguiente

1. De aquí en adelante se usarán las expresiones "Camino Real", "Tierra Adentro" o "Camino de Tierra Adentro", como abreviaturas del nombre completo "Camino Real de Tierra Adentro", sabiendo que dichas expresiones se refieren al nombre completo. 


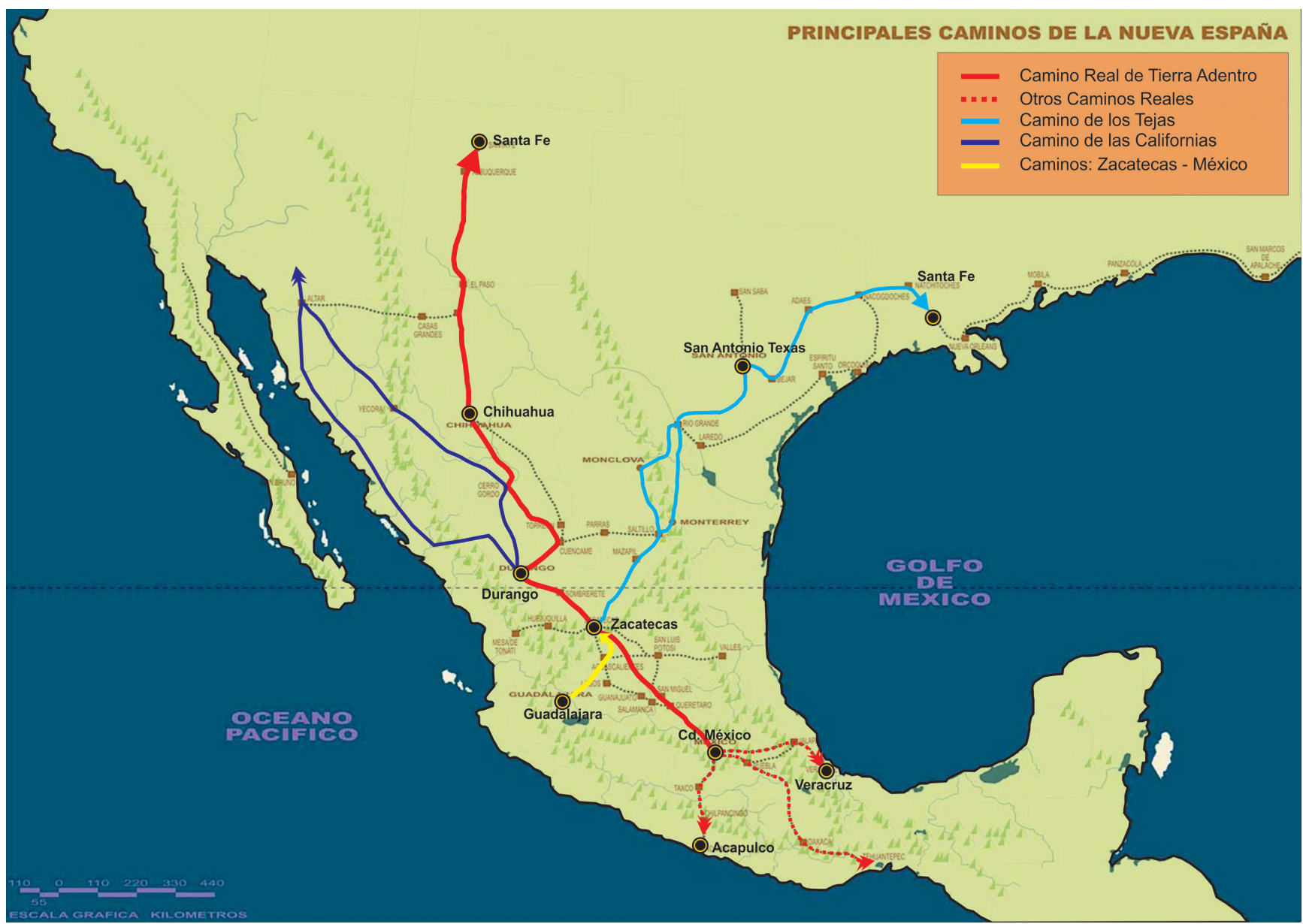

paso fue realizar una investigación histórica y documental complementaria, mediante la revisión de diferentes archivos históricos municipales, tales como el de Sombrerete, en Zacatecas; el de Durango; y los de Parral y Chihuahua, en el estado de Chihuahua. De estos archivos se han obtenido datos muy importantes, como el hecho de que los soldados y el capitán del cordón de presidios del Camino Real fueron financiados por los mismos habitantes de las poblaciones aledañas a cada uno, y que además había una partida que era pagada por vecinos de Sombrerete, tal como consta en varios expedientes que registran dichos pagos durante varios años. Por otro lado, los documentos de los archivos permiten comprender las justificaciones que se esgrimieron para fabricar estos presidios en un sistema defensivo. Además, existen series o grupos documentales sobre la milicia, el comercio y la habilitación de tropas (ropa, armas y sueldos), sobre todo, en el de Parral. Cabe notar que no se encontró mucha información respecto de la estructura o de los espacios que componían estos presidios.

Tras esta fase de investigación de archivo, se procedió a la segunda etapa, el trabajo de campo, el cual se llevó a cabo junto con algunos especialistas en el territorio y en el tema de presidios. Se realizó el reconocimiento de los distintos referentes naturales mencionados en los textos, así como la identificación de las edificaciones antiguas aún existentes en cada sitio, para así determinar el sitio específico en que estuvieron emplazadas estas construcciones militares, lo cual también se corroboró empleando información obtenida mediante entrevistas a los lugareños. Durante todo este proceso, se realizó un levantamiento fotográfico.

La última etapa consistió en interpretar la totalidad de la información obtenida, además de llevar a cabo estudios comparativos con otras regiones, y fortificaciones contemporáneas y de características arquitectónicas similares, y se elaboraron dibujos y
Figura 1. Caminos de la Nueva España. Diseño por R. Carrillo Acosta, sobre la base de Ocupación de la Nueva Vizcaya. Presidios en el Camino Real de Tierra Adentro, durante los siglos XVII y XVIII (pp. 79-80), por R. Carrillo, 2013. 


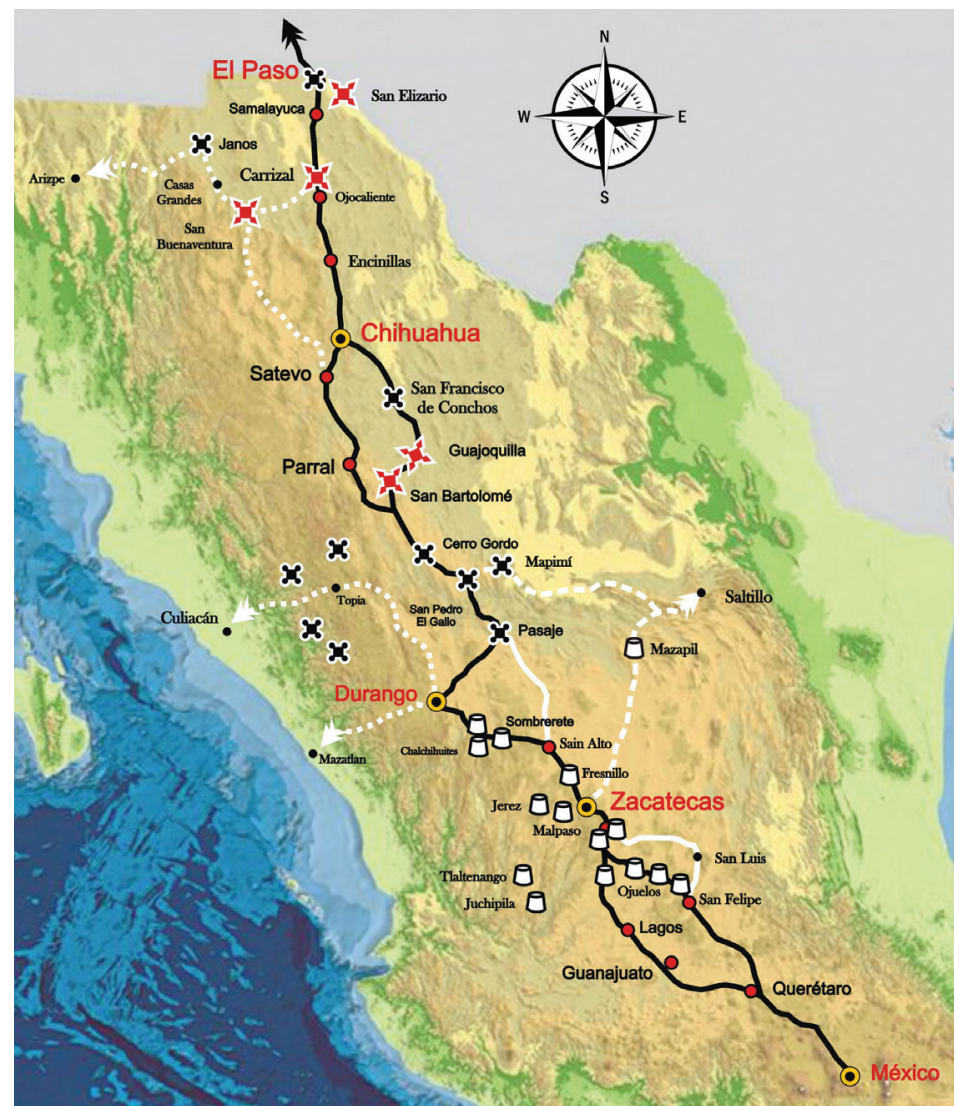

Figura 2. Presidios en el Camino Real de Tierra Adentro. Diseño por R. Carrillo Acosta, sobre la base de El Camino Real de Tierra Adentro (p. 84), por M. Vallebueno, 2011.

croquis. De esta manera, se procedió a la reconstrucción de espacios y estructura del Presidio del Gallo. Para este propósito, se realizó un levantamiento arquitectónico virtual del mismo, con varias vistas, para obtener una adecuada apreciación.

\section{Camino Real de Tierra Adentro}

En el México colonial, existieron diversas y variadas vías de comunicación llamadas caminos, término empleado para denominar todo aquel trazo comunicante entre centros de población, haciendas, minas o misiones religiosas, entre otros. Los había principales y secundarios, e incluso transversales. Estos alcanzaban todo el territorio del Imperio español, desde el siglo XVI hasta principios del XIX, momento en el cual, tras la guerra de Independencia mexicana y la guerra contra Estados Unidos, cambiaron radicalmente las jurisdicciones del territorio mexicano: la mitad norte del mismo pasó a pertenecer a Estados Unidos.

Alguno de estos caminos, incluso, fueron denominados caminos reales, por su gran trascendencia en los procesos de ocupación, en el desarrollo comercial, o por el simple hecho de permitir el desplazamiento de los viajeros a lo largo de grandes distancias. Entre los más importantes, se encuentran los que conducían de la ciudad de México hacia los puertos de Veracruz y Acapulco, ya que desde allí se establecía la conexión con Europa y Asia, respectivamente (ver Figura 1). También desde la ciudad de México, en el siglo XVI, se trazó el Camino de la Plata, que llegaba hasta Zacatecas, ruta por la cual se encaminaban las remesas de plata de las diversas minas del Imperio (Carrillo, 2013, pp. 79-80). 


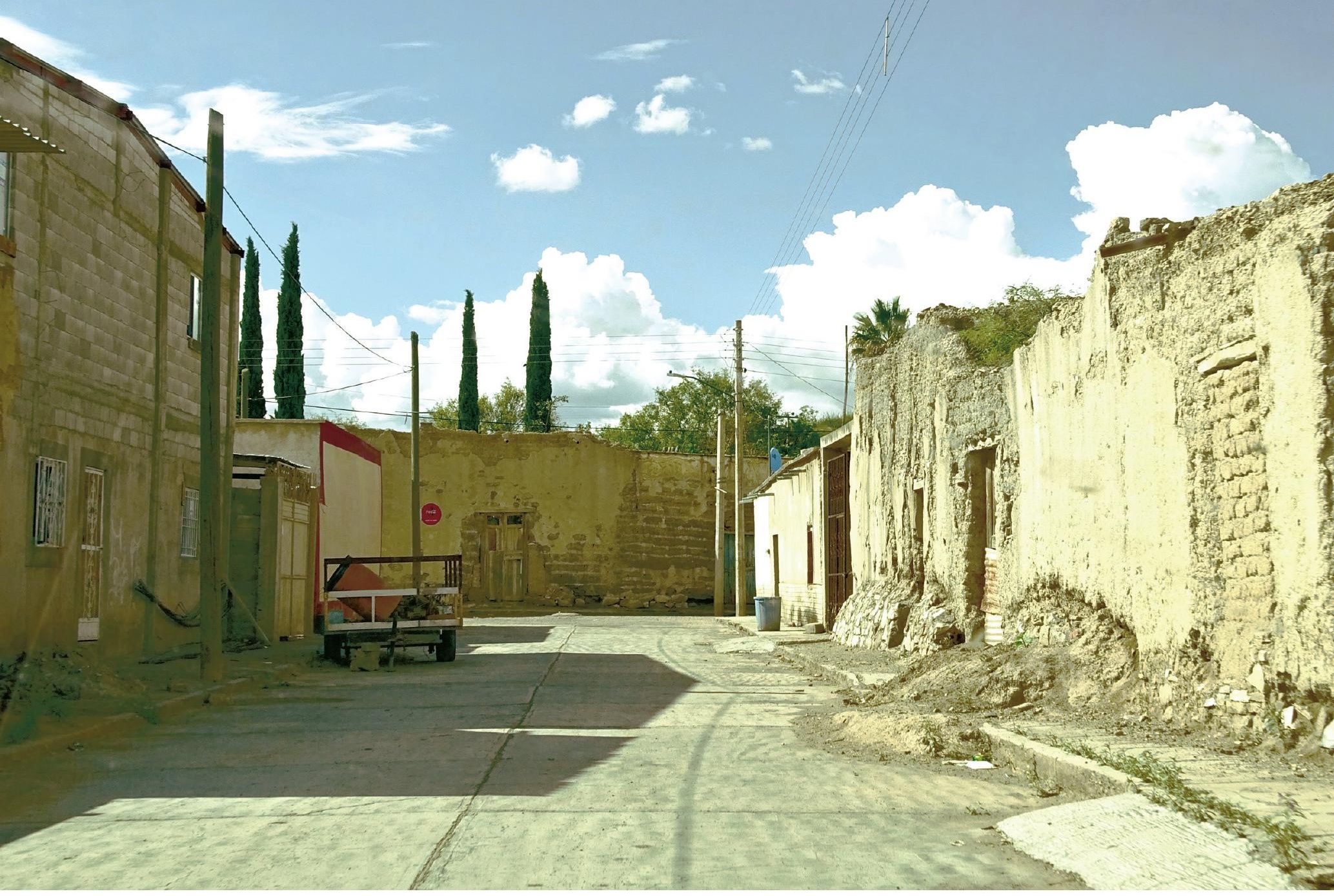

Desde Zacatecas se configuró uno más, rumbo al noreste, por San Antonio, Texas, en el actual Estados Unidos: un camino comercial que pasaba por Saltillo, donde se establecería una feria comercial para abastecer a todo el septentrión, que en ese entonces aún se encontraba bastante despoblado y alejado del centro administrativo. Este también fue un camino militar, donde se establecería una serie de presidios, sobre todo durante el siglo XVIII. Lo mismo sucedería por el lado occidente de México: desde Zacatecas y Durango partía un camino hacia las llamadas Californias, a lo largo del cual se asentarían una serie de misiones jesuitas y algunas franciscanas, que fueron clave en la pacificación y ocupación de esta región (ver Figura 1).

Finalmente, como se observa en la Figura 1, existía un camino central, muy extenso, que abarcaba todo el territorio del México colonial, desde el centro hasta el norte: el llamado Camino Real de Tierra Adentro. Este comenzaba en la ciudad de México y se internaba hacia el norte por Zacatecas, Durango y Chihuahua hasta llegar a Santa Fe, en Nuevo México. En torno a ese camino, se fueron estableciendo centros de población, minas, haciendas y misiones; después, se construyeron presidios para resguardar a los viajeros y la frontera. Con el tiempo, a esta ruta se le llamó también Tierra Adentro (Figura 2).

\section{Presidio de San Pedro del Gallo}

El presidio fue construido en 1687, y se ordenó su eliminación, junto a los demás que existían en la región, para 1751, cuando se suponía que la región estaba pacificada. Únicamente quedó el presidio de El Pasaje, aunque de manera intermitente, ya que
Figura 3. Pueblo de San Pedro del Gallo. Fotografía por R. Carrillo Acosta, 25 de julio de 2017. 
Figura 4. Calle de San Pedro del GaIlo. Fotografía por R. Carrillo Acosta, 25 de julio de 2017. pasó de ser presidio a población y de población a presidio en varias ocasiones. Las tropas que ocupaban dichos fuertes fueron llevadas más al norte, hacia la línea fronteriza de presidios que se terminó de formar a finales del mismo siglo; no obstante, algunos de los soldados se quedaron y fundaron poblaciones civiles en esos espacios, adaptando la estructura de cada presidio a sus necesidades, por lo cual hoy en día existen municipios que llevan el nombre de los antiguos presidios, como es el caso del municipio de San Pedro del Gallo.

La mayor parte del territorio que ocupa el actual San Pedro del Gallo $(2,008.3 \mathrm{~km} 2)$ está ubicado en los terrenos altos de la meseta de La Zarca. Limita al norte con los municipios de Mapimí e Hidalgo; al oriente con Mapimí y Nazas; al sur con Nazas y San Luis del Cordero; y al poniente con Indé y Rodeo.

La primera parte del nombre del poblado, San Pedro, es de carácter religioso, aunque fue mucho después que se construyó un templo en honor a su patrono, en el año de 1745, cuando estaba en decadencia el presidio. Del templo, que se hizo para conmemorar a San Pedro Apóstol, se conserva también la torre, que fue construida años después, en 1891. Tanto el templo como la torre son fuente de presunción para los pobladores de la cabecera municipal. Respecto de la segunda parte del nombre del presidio, describe la tradición oral que "en una ocasión a unos arrieros se les desbandó un gallo que corrió y se metió al antiguo ojo de agua, que ahora está casi seco, pero antes era frondoso y pantanoso, nunca encontraron al gallo. Pero rememoran los mayores, que desde entonces a todos los caminantes o viajeros que se acercaban a beber 


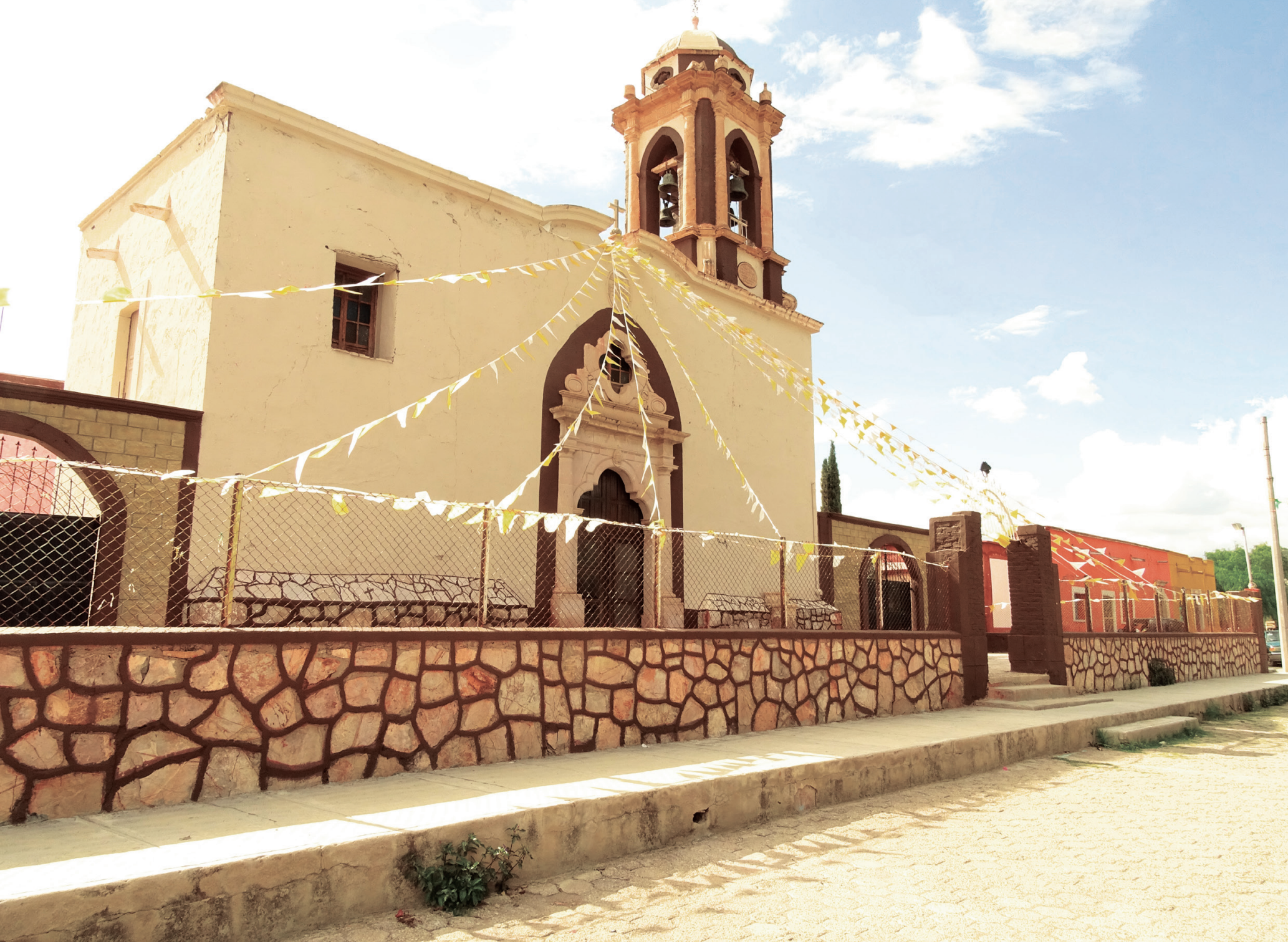

agua para mitigar el calor, el gallo les cantaba, por eso el municipio hoy se llama San Pedro del Gallo" (Centro Inah Durango, 2005, p. 1). Al margen de la tradición oral, lo cierto es que sí fue por el ojo de agua que se eligió ese lugar para establecer el presidio, emplazamiento desde el cual eventualmente surgiría una población (Vallebueno Garcinaba, 2011, p. 255). Cuando el presidio dejó de serlo, en el siglo XVIII, se edificaron en su entorno construcciones de carácter civil, de las cuales aún hay evidencia (ver Figura 3). Parte de sus calles todavía es de terracería, como antaño, así esta la que da paso al templo de San Pedro, como se puede observar en la Figura 4.

Con estos breves antecedentes históricos y la investigación documental, se procedió a la investigación de campo del tramo del Camino Real, en Durango, sobre todo con la intención de proceder a la identificación de los edificios o evidencias donde se supone que se albergaron estas fortificaciones, entre ellas la del Gallo. De esta manera, se emprendió la identificación a cargo de un grupo de investigación conformado por la doctora Chantal Cramaussel, Salvador Alfredo Álvarez Suarez, Nora Edith Jiménez Hernández y Miguel Vallebueno, todos doctores en historia y especialistas en el tema de la región, además de una tesista, Diana Aguilar Borjón, y un servidor. Se visitaron los espacios del presidio de El Pasaje, Mapimí y el de Pedro del Gallo, además de otros sitios o espacios fortificados de la región, tales como haciendas, puentes y templos, lo cual será motivo de futuras publicaciones. Interesa, por ahora, el caso que aborda el presente estudio.

A pocos metros del templo, al cruzar algunas calles, fue posible identificar el sitio donde estuvo establecido el presidio, gracias a las investigaciones, a las indicaciones y la
Figura 5. Templo de San Pedro. Fotografía por R. Carrillo Acosta, 25 de julio de 2017. 


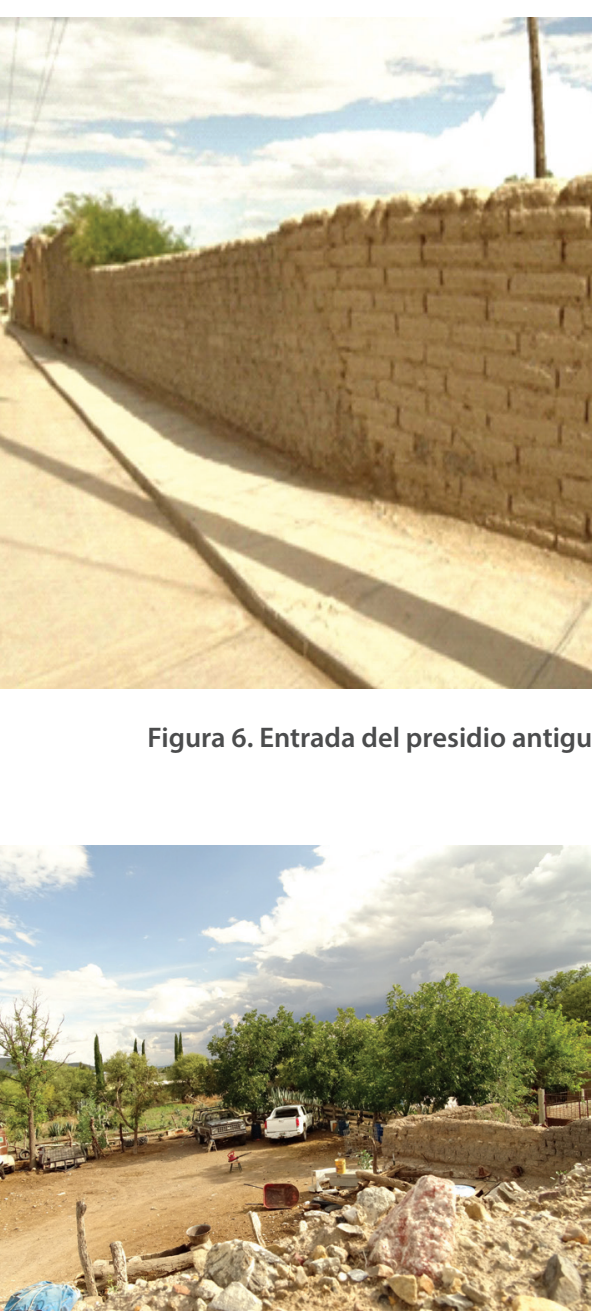

Figura 7. Antigua plaza del presidio y su uso actual. Fotografía por R. Carrillo Acosta, 25 de julio de 2017

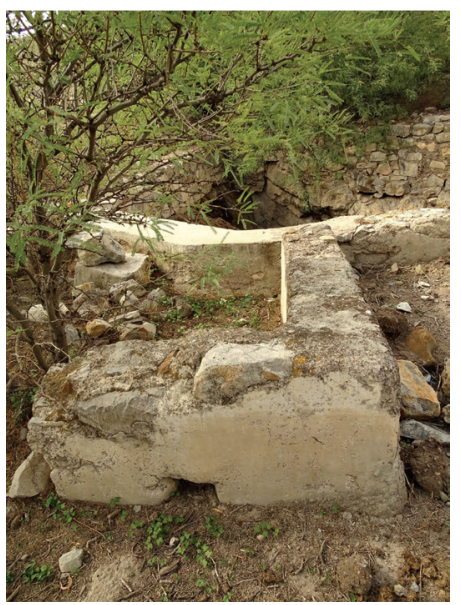

Figura 8. Noria del presidio. Fotografía por R. Carrillo Acosta, 25 de julio de 2017. guía de los vecinos, así como a la observación directa y el análisis. De esta manera, fue posible constatar el estado ruinoso del lugar, el estado de abandono en el que se encontraba, y poco aprovechamiento y uso: los habitantes de San Pedro de Gallo utilizan solo una mínima parte de toda la extensión de lo que fue el presidio, aunque es gracias a ello que no se ha destruido por completo. Del edificio original ya solo quedan la barda del acceso principal, y, por dentro, la noria y algunos cuartos caídos, destechados, que correspondían a la casa de guardia y, posiblemente, a la casa del capitán (ver Figuras $6,7,8,9$ y 10).

En parte, el presidio fue identificable gracias a la noria y al ojo de agua, el cual está en las afueras del edificio $y$, aunque ya no hay afluente del vital líquido, permanece resguardado por un cuarto (ver Figura 11). En la parte posterior de la construcción, también se pudo identificar el emplazamiento de las caballerizas, ya que a través de una acequia se conducía el agua desde el ojo hasta allí, como se puede observar en la Figura 12. Un descubrimiento interesante fue que en el muro principal, más delante de la entrada o acceso principal, es posible observar las etapas constructivas (ver Figura 13).

\section{Reconstrucción material}

Otro elemento que permitió identificar la estructura y dimensiones del presidio antiguo fue la construcción de una réplica de este que se hizo en las afueras del pueblo. Esta se realizó con material contemporáneo, simulando la edificación original: se puede observar su modelo cuadrado, con torreones y una gran plaza al centro, rodeada por las cuatro bardas perimetrales. Al parecer, los arquitectos del INAH (Instituto Nacional de Antropología e Historia) de Durango se encargaron de hacer dicha réplica, pero no se sabe con certeza, así como la fecha de su realización (ver Figura 14).

Para poder evaluar el sitio de interés, el Presidio del Gallo, es necesario tomar en cuenta la estructura básica que tenía un presidio de esas características en la región.

Los presidios por lo regular eran de grandes dimensiones; ocupaban por encima de $10,000 \mathrm{~m}^{2}$ y alcanzaban como máximo los $122,000 \mathrm{~m}^{2}$ (Carrillo Acosta, 2013, pp. 11-12). Los modelos constructivos empleados en los presidios fueron muy diversos, pero fundamentalmente se trató de tres: cuadrado, rectangular y poligonal. Independientemente de ello, todos estaban cercados por grandes y gruesas murallas, también llamadas bardas perimetrales o cortinas (salvo algunas excepciones, de modelo abierto) (Carrillo Acosta, 


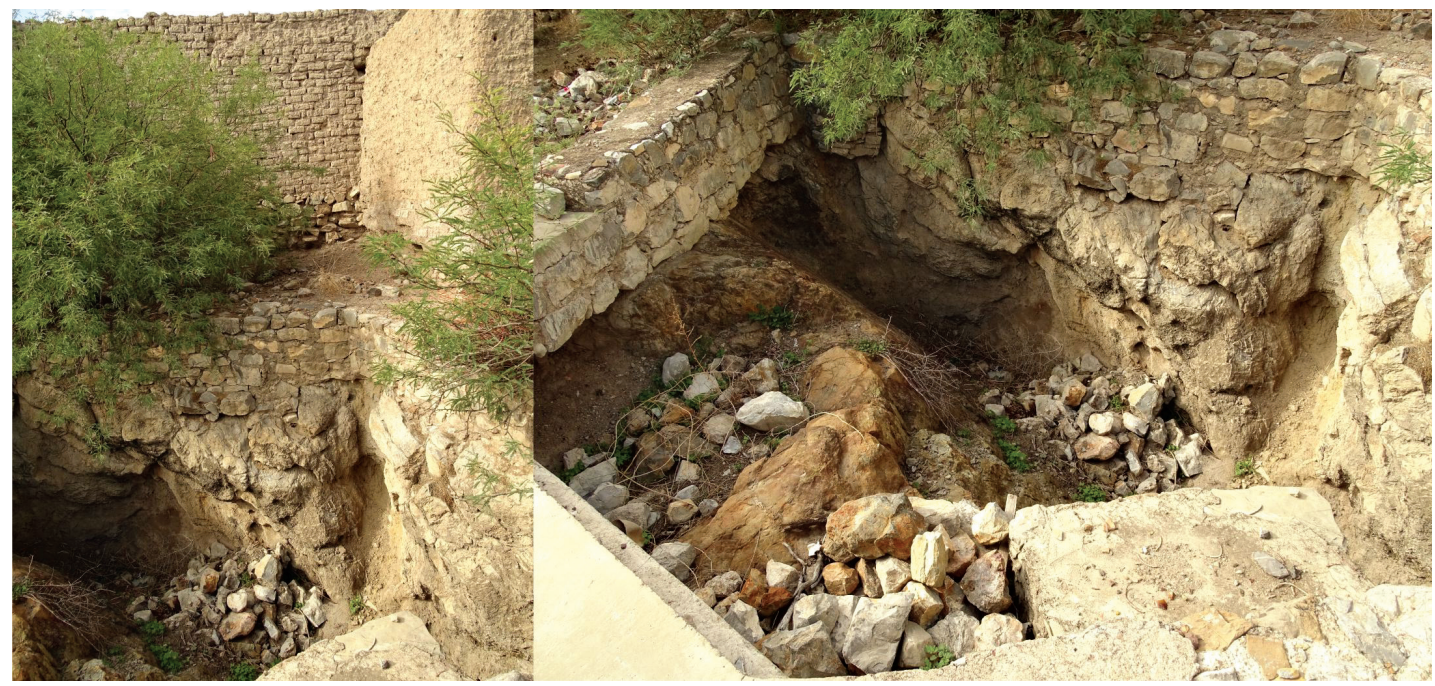

Figura 9. Ojo de agua en el interior del presidio. Fotografía por R. Carrillo Acosta, 25 de julio de 2017.

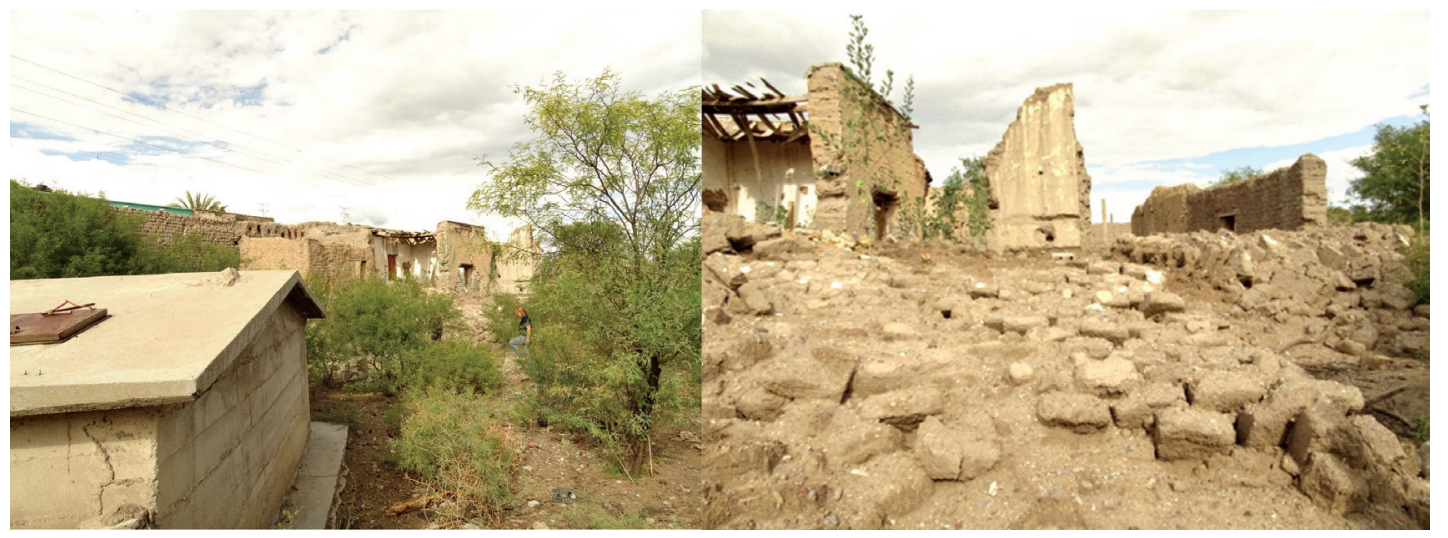

Figura 10. Casas de la guardia y del capitán del presidio. Fotografía por R. Carrillo Acosta, 25 de julio de 2017.

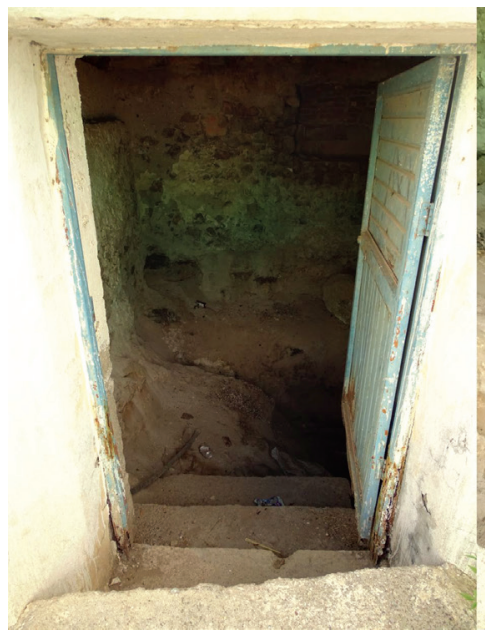

Figura 11. Entrada al ojo de agua. Fotografía por R. Carrillo Acosta, 25 de julio de 2017.

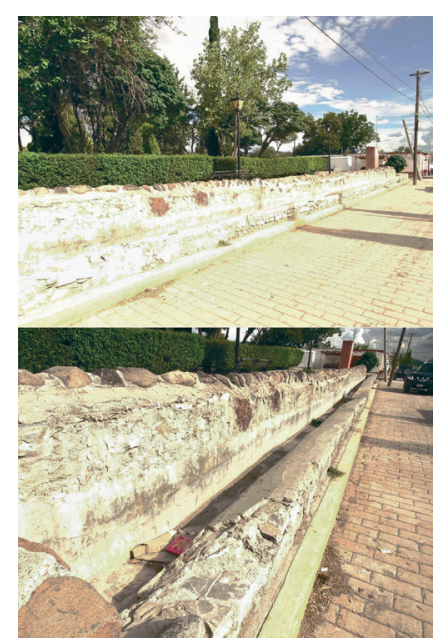

Figura 12. Acequia del presidio. Fotografía por R. Carrillo Acosta, 25 de julio de 2017. 


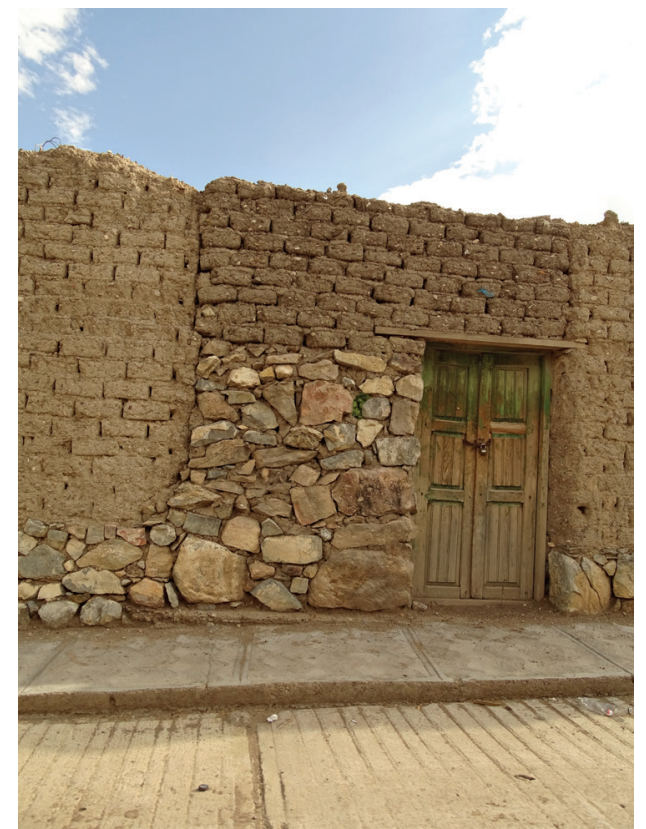

Figura 13. Muro principal del presidio. Fotografía por R. Carrillo Acosta, 25 de julio de 2017.
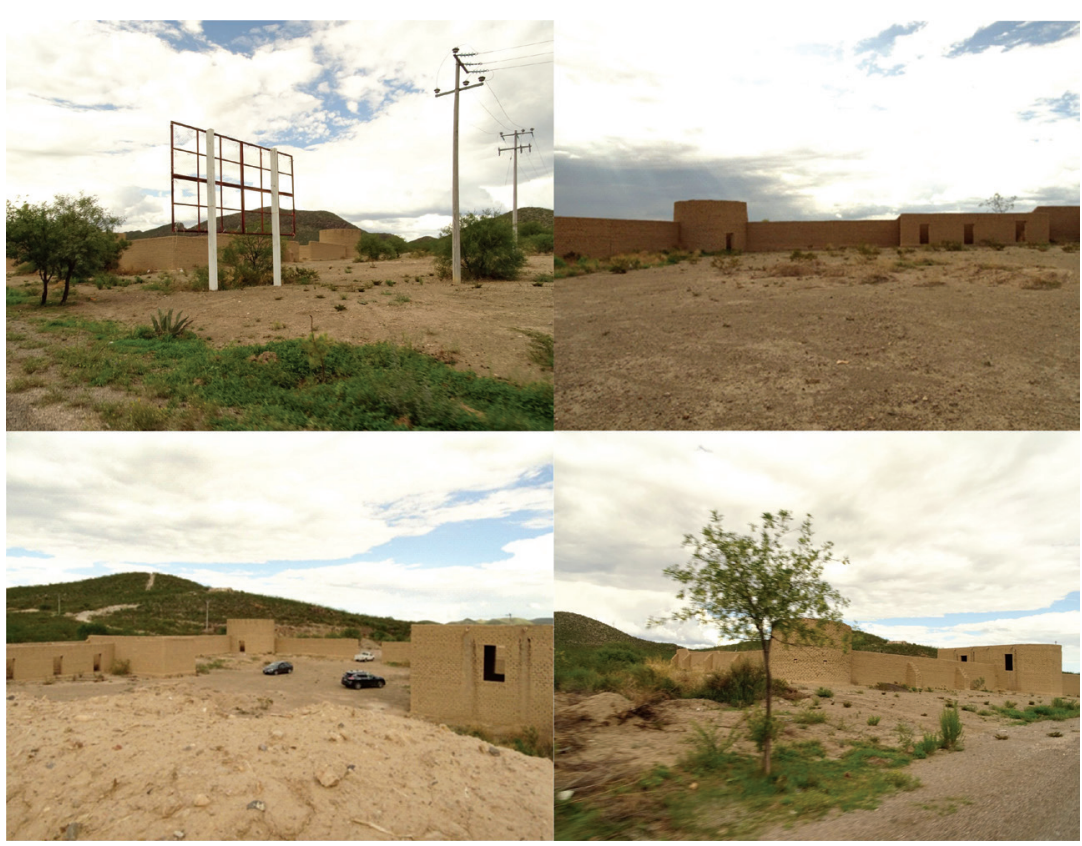

Figura 14. Réplica del presidio del Gallo. Fotografía por R. Carrillo Acosta, 25 de julio de 2017.

2013, pp.14-44; Carrillo Acosta \& Castillo Ruiz, 2017, pp.104-113). Una diferencia importante respecto de otras construcciones fortificadas fue la presencia de torreones, cuyo número oscilaba, por pares, entre dos y ocho, según el tamaño de la construcción y los frentes que había que proteger. Los había cuadrados, cilíndricos y pentagonales; cualquiera que fuera el tipo de torreón presentaba orificios alargados y delgados, llamados aspilleras, que no eran otra cosa que mirillas a través de las cuales disparaban a los atacantes.

La estructura base del Presidio del Gallo se conoce gracias a la visita que realizó el ingeniero militar Nicolás de Lafora en 1766, cuando ya no operaba el sitio como presidio, sino como poblado civil. De Lafora describió lo que quedaba del puesto militar como "una plaza cuadrada, con dos torreones circulares, diagonalmente opuestos para flanquear las cortinas. Tres de estos muros servían para levantar las casas de los soldados, en el cuarto estaba la entrada principal, donde había unos pórticos que servían de cuerpo de guardia" (Vallebueno Garcinaba, 2011, p. 255).

En la Figura 15, se observa la disposición y dimensión del presidio, así como las construcciones de población civil asentadas en las afueras del mismo, tanto indígenas como de las familias de los soldados. En el interior, se observa la agrupación de las habitaciones de soldados en la esquina posterior, formada por dos muros. El tercer muro, el de la izquierda, del cual se desprende una serie de tres cuartos para habitación del capitán, es el que está cercano a la noria, cuya construcción no está adosada al muro sino hacia el interior del presidio. Sobre ese mismo muro de la izquierda, se aprecia que está incrustada la capilla, entre el mismo muro, mirando hacia el exterior del presidio. Finalmente, en la parte posterior, se aprecian las caballerizas.

Como se observa, el presidio no contaba con mayores detalles arquitectónicos de tipo militar, además de los básicos: una gran plaza de armas rodeada de una muralla por sus cuatro lados, dos torreones en sus esquinas (en uno de ellos se guardaba el armamento y granos), habitaciones de soldados y, quizá, celdas para los presos, aunque estas probablemente se improvisaban en la habitación de algún soldado, ya que no se trataba de una cárcel como tal, sino de un puesto militar. Ya muy avanzado el siglo XIX, 


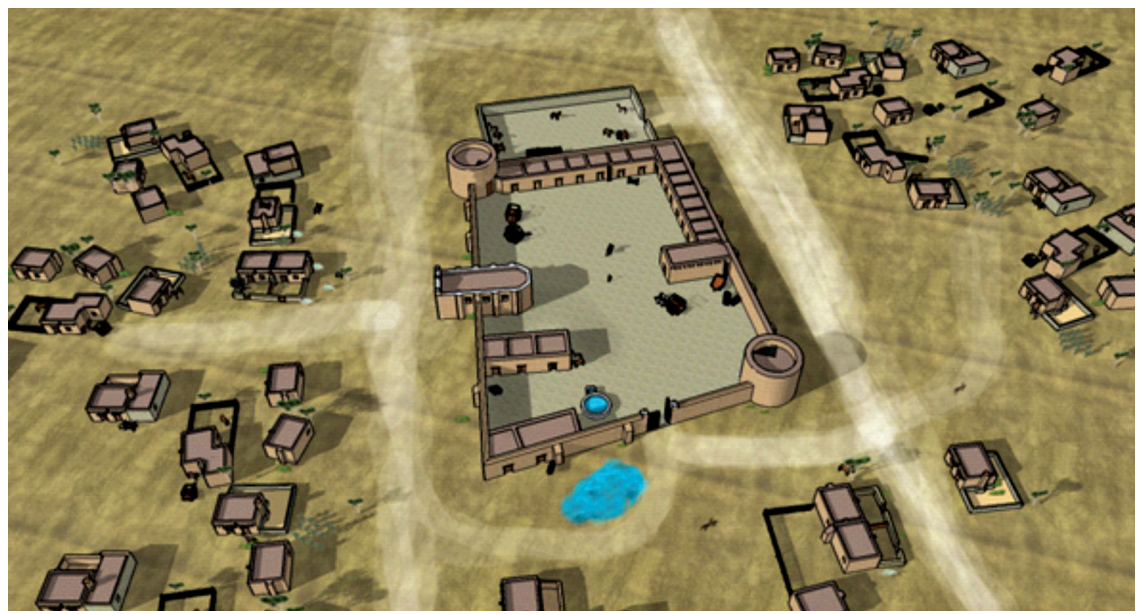

Figura 15. Presidio del Gallo. Diseño por R. Carrillo Acosta, sobre la base de AHMP, 1723, expediente 24, 17 fojas.

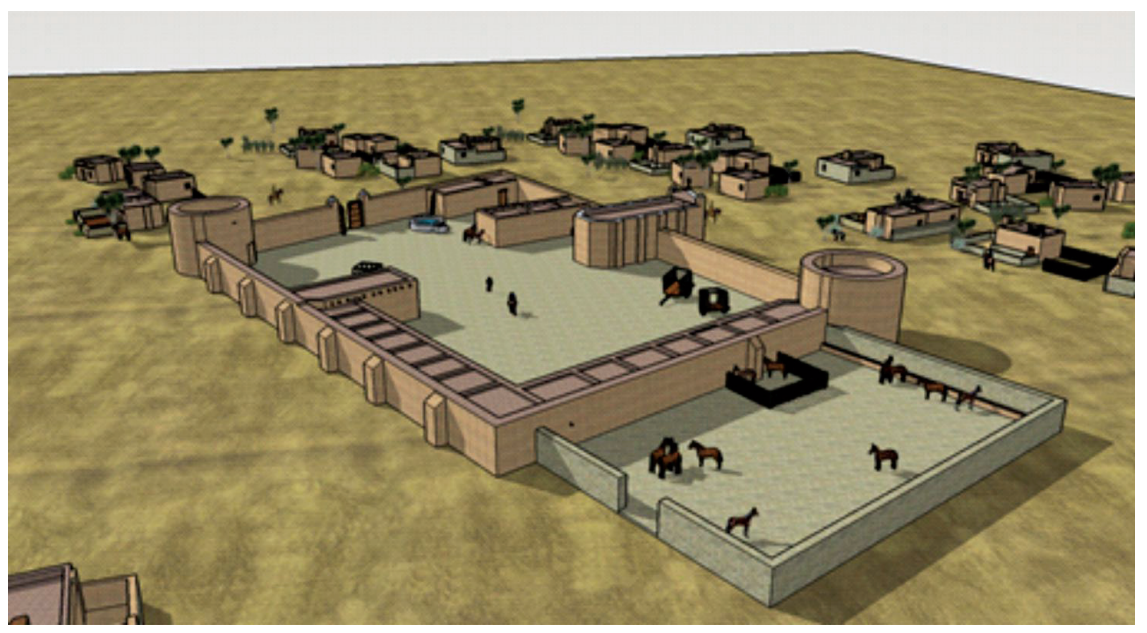

Figura 16. Levantamiento arquitectónico del presidio del Gallo. Diseño por R. Carrillo Acosta, sobre la base de AHMP, 1723, expediente 24, 17 fojas.

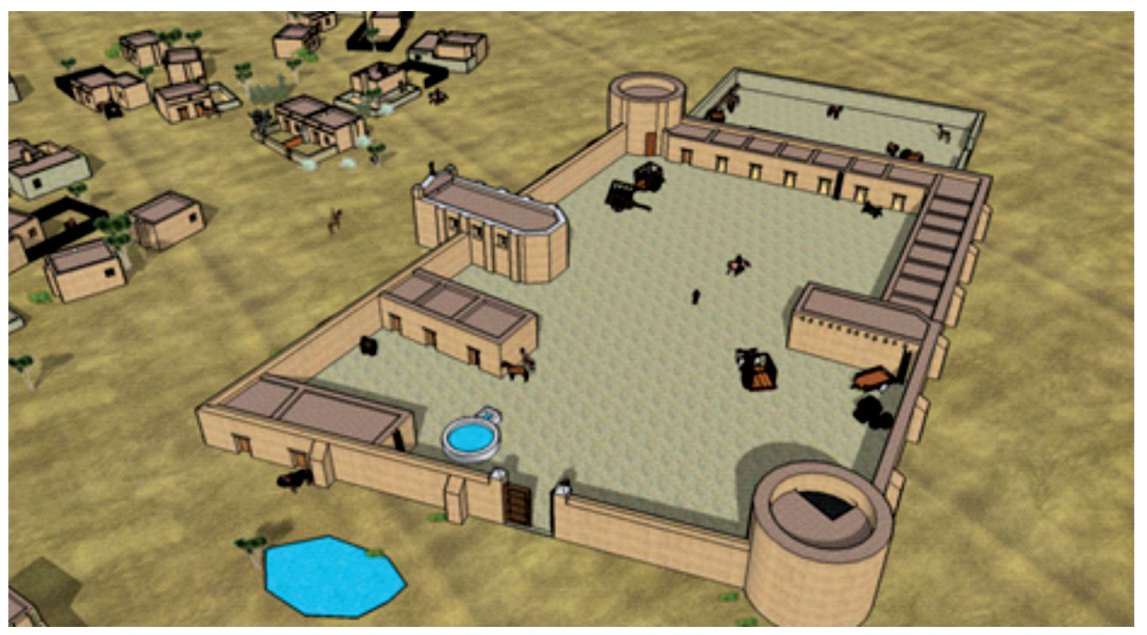

Figura 17. Interior del Presidio del Gallo. Diseño por R. Carrillo Acosta, sobre la base de AHMP, 1723, expediente 24,17 fojas. 


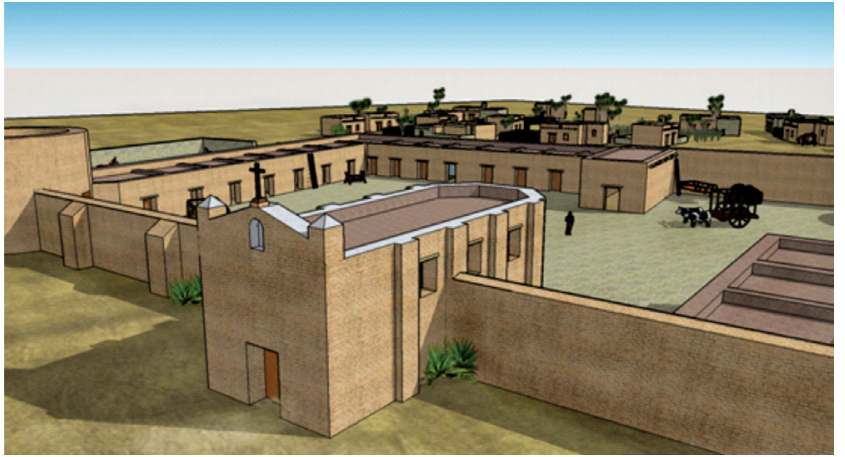

Figura 18. Capilla del presidio. Diseño por R. Carrillo Acosta sobre la base de AHMP, 1723, expediente 24, 17 fojas.

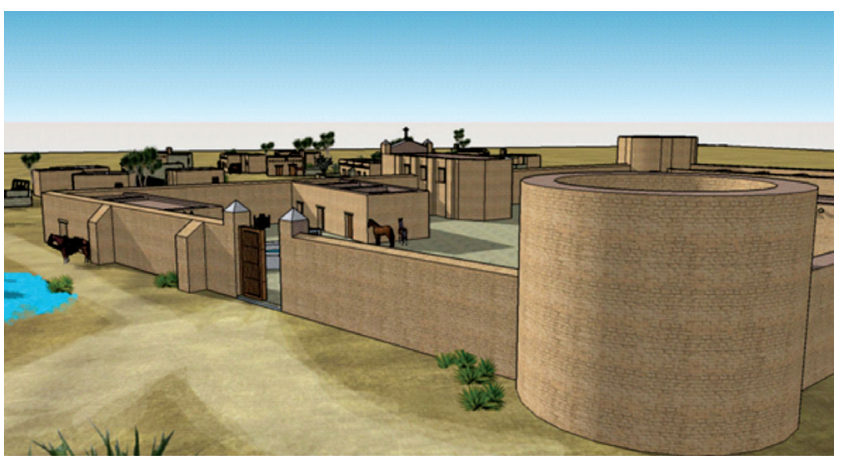

Figura 20. Entrada principal al presidio. Diseño por R. Carrillo Acosta sobre la base de AHMP, 1723, expediente 24, 17 fojas.

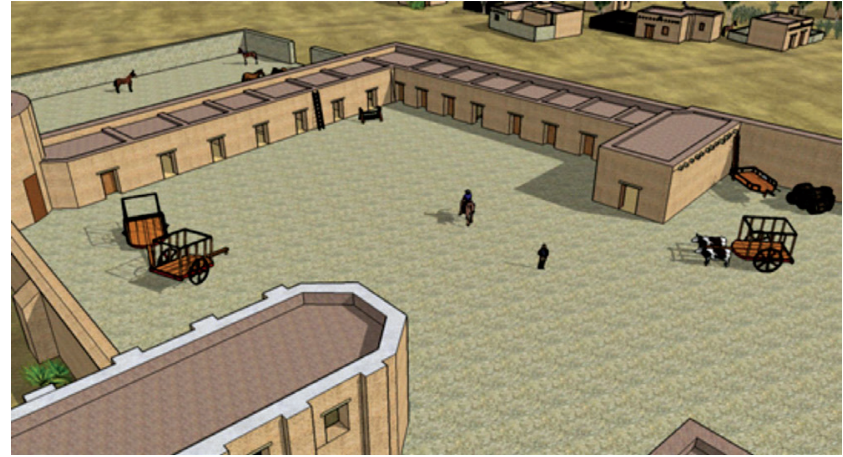

Figura 19. Habitaciones de los soldados. Diseño por R. Carrillo Acosta sobre la base de AHMP, 1723, expediente 24, 17 fojas.

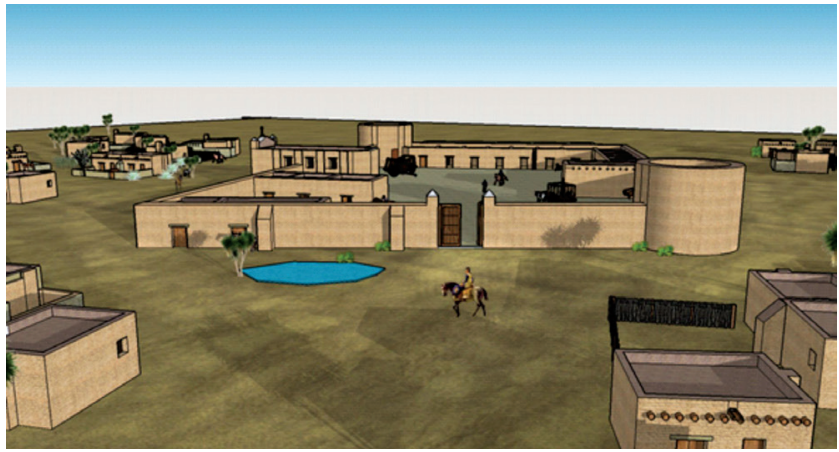

Figura 21. Vista frontal del presidio. Diseño por R. Carrillo Acosta sobre la base de AHMP, 1723, expediente 24, 17 fojas.

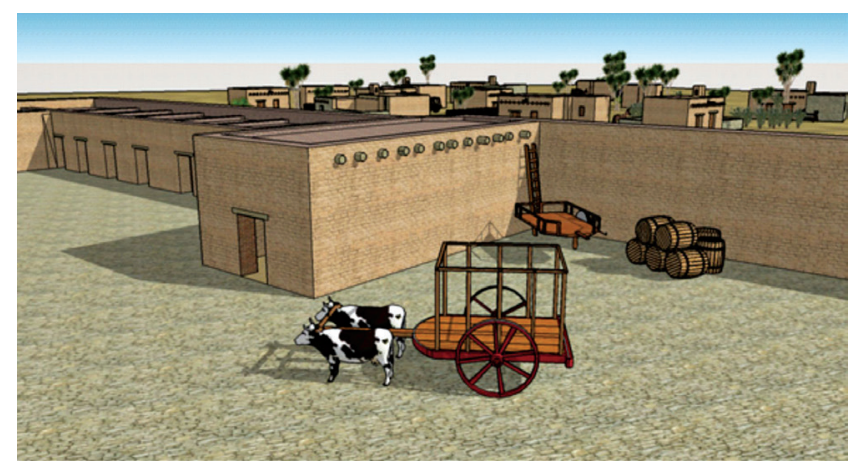

Figura 22. Vista desde el interior del presidio. Diseño por R. Carrillo Acosta sobre la base de AHMP, 1723, expediente 24, 17 fojas.

algunos de los presidios sí se adaptaron para albergar celdas, manteniendo la misma estructura bajo el nombre de presidios y presidiarios, pero refiriéndose ahora a los presos y no a soldados de presidio.

Tras culminar la investigación documental y de campo, se realizó una propuesta de reconstrucción de este presidio, que resultó como se observa en la Figura 16.

En la Figura 17, se aprecia la entrada principal. A su izquierda, adosado al muro principal, está el cuerpo de guardia, que cuenta con entradas independientes a la principal. 


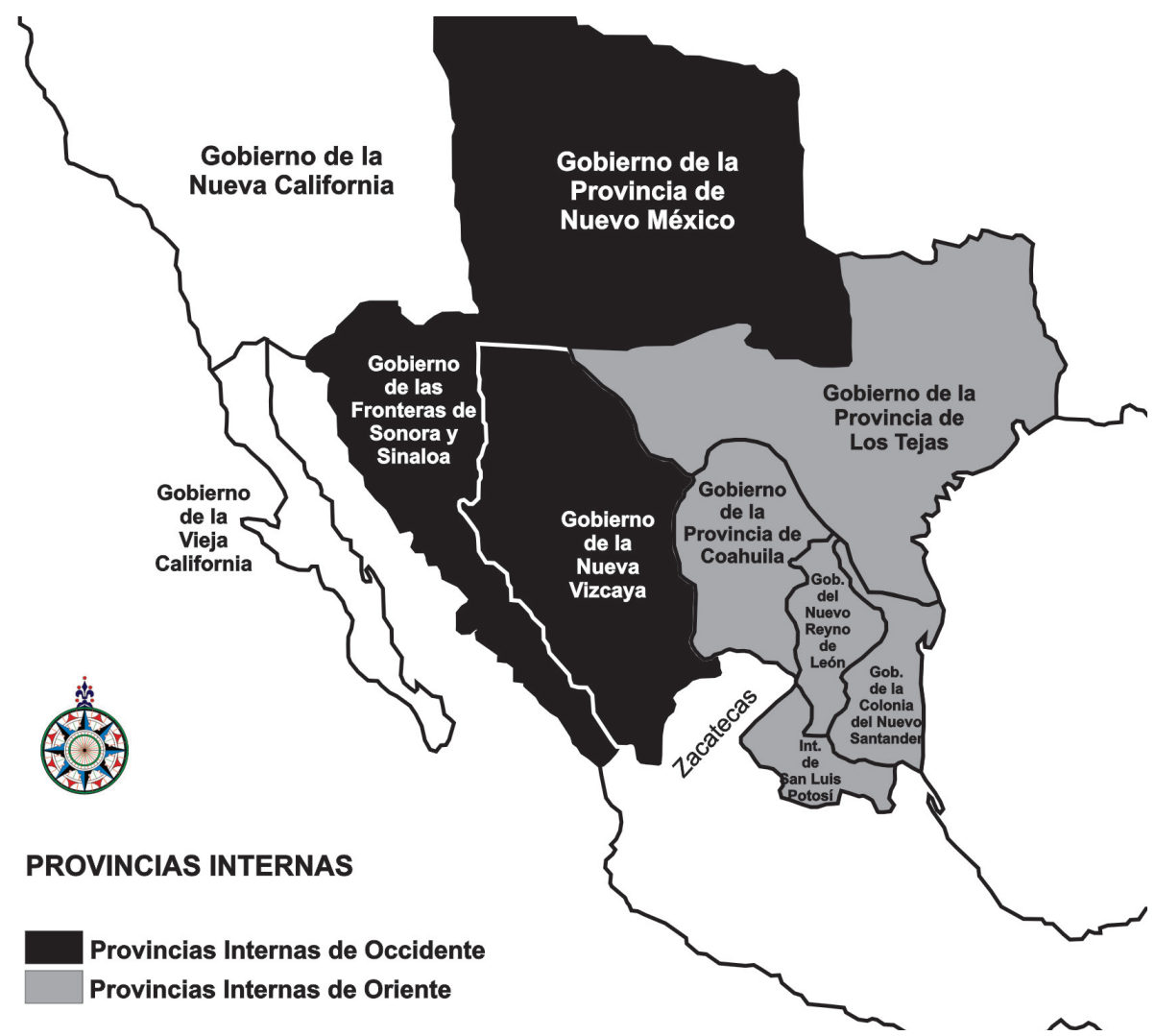

Figura 23. Provincias internas en el norte de México. Diseño por R. Carrillo Acosta, sobre la base de El gran norte de México. Una frontera imperial en la Nueva España (p. 133), por A. Jiménez, 2006.

Hacia adentro, por el muro de la izquierda, se aprecian las habitaciones del capitán; después de estas, se disponía la capilla, la cual debía tener entrada por el exterior del presidio, para mantener separado el aspecto religioso del militar y permitir el ingreso de la población civil. También se observa el ojo de agua en las afueras del presidio, justo frente a él por la entrada principal, como se aprecia en las Figuras 15 y 17.

\section{Presidios en la Nueva Vizcaya}

Los presidios eran construcciones fortificadas a manera de sistemas defensivos, regularmente de gran tamaño, que albergaban una guarnición de soldados, cuya función principal era brindar protección a los viajeros que transitaban los caminos. Además, estaba contemplado que fungieran como asentamientos de población española; por ello, se construyeron chozas para habitación de las familias de los soldados, las cuales se asentaban en las afueras de cada presidio; de esa manera, se protegía el territorio y a la vez se poblaba.

Esa fue la dinámica que tuvo lugar en el norte de México, a lo largo del Camino de Tierra Adentro, el cual atravesaba el territorio o reino conocido como De la Nueva Vizcaya. Ese sector del México colonial, dividido en reinos o gobernaciones, abarcaba básicamente los actuales estados de Durango y Chihuahua; el resto de gobernaciones se pueden observar en la Figura 23.

La jurisdicción de dichas gobernaciones fue variando con el paso del tiempo. Hubo diversos reacomodos, pero el esquema que dominó en el norte fue el de las llamadas 


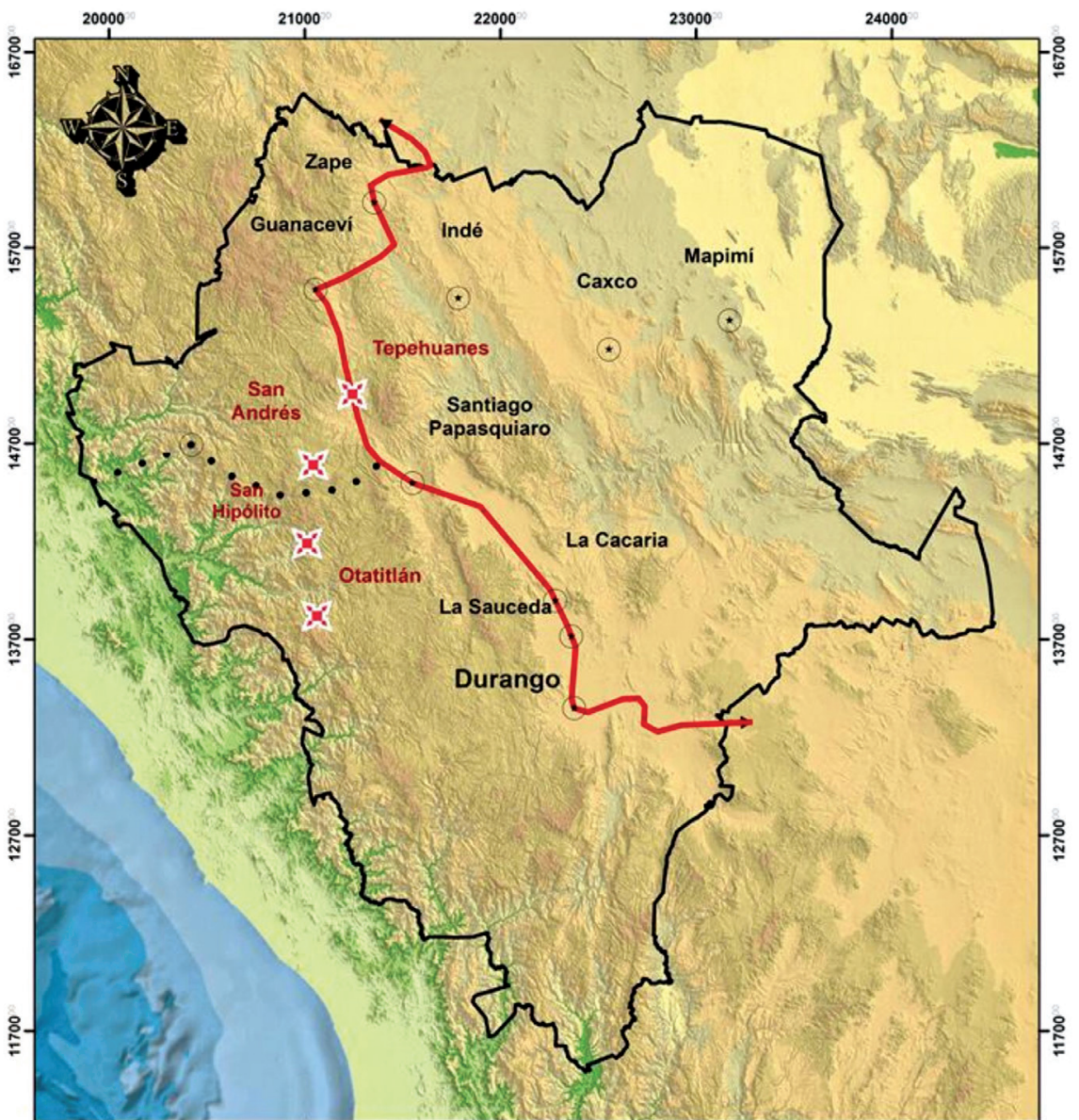

Figura 24. Presidios misión. Diseño por R. Carrillo Acosta, sobre la base de Ocupación de la Nueva Vizcaya. Presidios en el Camino Real de Tierra Adentro, durante los siglos XVII y XVIII (p. 148), por R. Carrillo Acosta, 2013.

comandancias o provincias internas, el cual dividía el territorio en comandancias o provincias de Occidente y Oriente (ver Figura 23).

La ocupación poblacional de la Nueva Vizcaya comenzó en el siglo XVIl y en ese entonces se crearon 10 presidios a lo largo del trayecto del Camino de Tierra Adentro, ocho en Durango y dos en Chihuahua. Existían otros fuera del tramo principal, en ramales o trazos secundarios. En principio, el Camino de Tierra Adentro se trazó por el occidente de Durango; allí se construyeron los presidios de San Hipólito, San Andrés, Otatitlán y Santa Catalina de Tepehuanes, entre 1600 y 1620, llamados presidios misión, pues brindaban protección a las misiones emplazadas en las cercanías (Carrillo, 2013, pp. 131-149) (ver Figura 24).

En 1620 se estableció el presidio de Mapimí, cuya permanencia fue muy oscilante, ya que atravesó poblamientos y despoblamientos, según la prosperidad o crisis de sus vetas mineras. En 1632, al descubrirse las ricas minas de Parral, el trazo del Camino Real se desplazó hacia el costado oriente de Durango. Por ello, entre 1646 y 1689 se ordenó la construcción de nuevos presidios en ese trayecto, cuya ruta se mantuvo hasta ya entrado el siglo XIX. A lo largo de esta vía, se establecieron los presidios de El Pasaje, Mapimí, del Gallo y Cerro Gordo, en Durango; y los de Conchos y El Paso, en Chihuahua (Carrillo, 2013, pp. 149-177). En la presente investigación, se pretende analizar cómo se desarrolló esta creación de presidios, en tanto cordón defensivo del camino y la fron- 


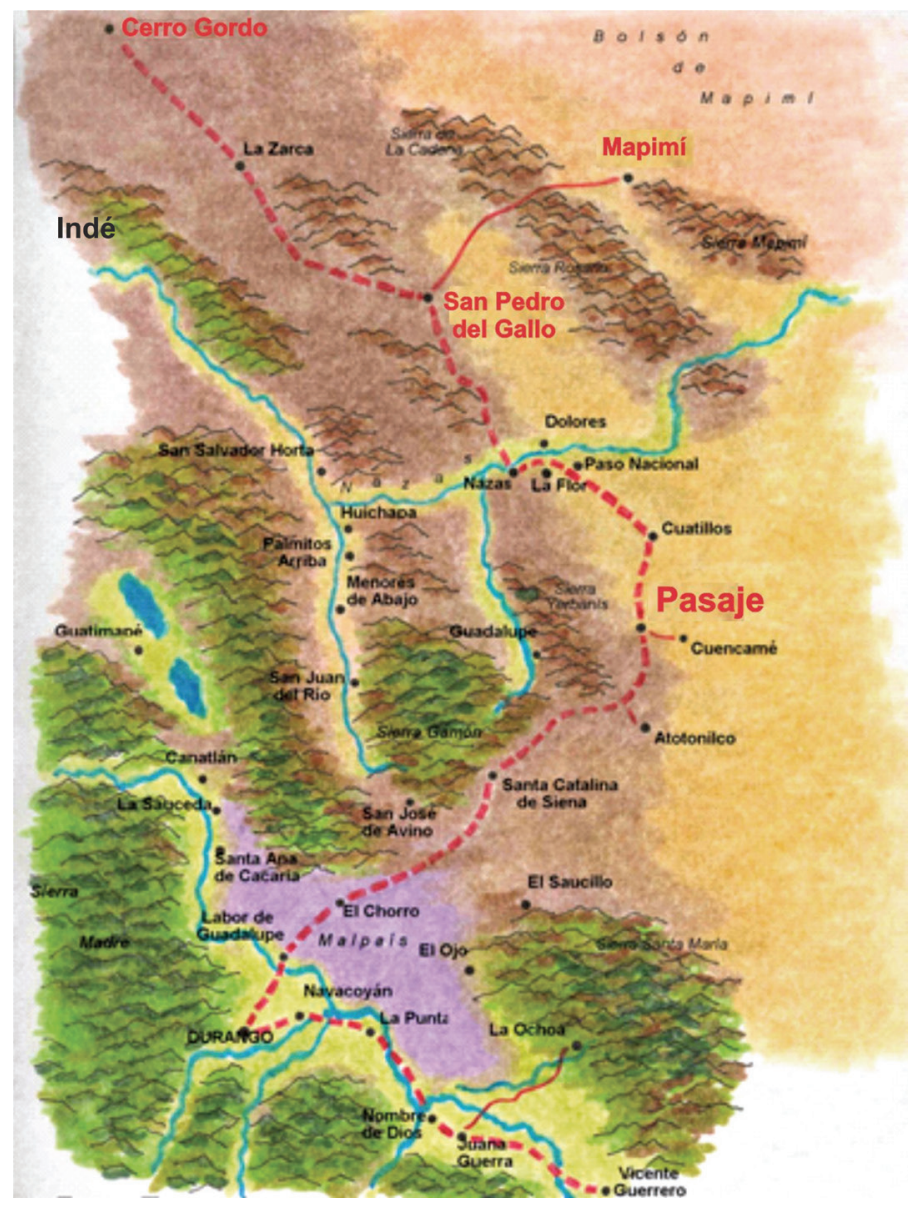

Figura 25. Cordón defensivo en el Camino Real en Durango. Elaborado sobre la base de Documentación de bienes del patrimonio cultural asociados al Camino Real de Tierra Adentro (p. 9), por Centro Inah Durango, 2005.

tera (ver Figura 25), con énfasis en la parte correspondiente a Durango, donde estaba ubicado el presidio de San Pedro del Gallo.

A principios del siglo XVII, se trazó una nueva ruta que comenzaba en Zacatecas, continuaba por Sain Alto y luego se dirigía directamente hacia El Pasaje, en Cuencamé, y de ahí hasta Parral, ruta más directa hacia las minas recién descubiertas; el camino anterior iba por Santiago Papasquiaro, Tepehuanes y Guanaceví, pero también por Durango, San Juan del Río e Indé. Con la habilitación de este nuevo trazo del Camino Real, se fueron gestando nuevas poblaciones a lo largo de su trayecto y se intensificó el tráfico de arrieros, militares y misioneros por la parte poniente de esa región tepehuana. El camino de retorno era diferente, pues los viajeros debían pasar por la ciudad de Durango, ya que allí se encontraba la Caja Real y la sede de la gobernación de la Nueva Vizcaya, de tal manera que de Cuencamé se llegaba a Durango y de ahí se seguía por la ruta tradicional a Zacatecas, atravesando Sombrerete. Con el tiempo, el recorrido pasó a realizarse por la misma ruta de Durango tanto de ida como de vuelta (ver Figura 2).

La incipiente ocupación de la parte oriental del actual estado de Durango suscitó conflictos con los indios salineros, tobosos, conchos y tarahumaras, pues los españoles estaban invadiendo su territorio; no obstante, este camino acabó siendo el predilecto por viajeros y arrieros, y se convirtió muy pronto en la arteria principal de la ruta, por lo que se le denominó Camino Real de Tierra Adentro (ver Figura 2). 
devenir Vol. 6, Nº11, ENERO - JUNIO 2019, PP. 9-24 - ESTUDIOS I ISSN 2312-7562 | E-ISSN 2616-4949

UNIVERSIDAD NACIONAL DE INGENIERÍA, LIMA

doi: https://doi.org/10.21754/devenir.v6i11.631

\section{Conclusiones}

Los presidios del norte del Camino Real en México eran diferentes, ya que debían ser de grandes dimensiones, como una pequeña ciudad, lo cual sí cumplían, pues tenían todos los servicios que requería una población y todas las condiciones para serlo. Ya en los últimos presidios que se establecieron sobre la frontera de Chihuahua y Nuevo México se fueron integrando más elementos, tales como una escuela de primeras letras, molinos, tiendas, aduanas, entre otros. De estos presidios o construcciones fortificadas nacieron las actuales poblaciones, que han mantenido el nombre de cada presidio; desafortunadamente, no se conservan los edificios originales completos y en muchos casos ya no queda nada en pie.

Falta mucho por hacer en pos de la investigación sobre las fortificaciones emplazadas en la sección norte del Camino Real de Tierra Adentro, de forma que se pueda difundir su importancia para conseguir su conservación, reconstrucción y puesta en valor. Se espera que este trabajo sea una contribución valiosa a la difusión de la relevancia de este patrimonio, pero, sobre todo, que opere como constructor o generador de conciencia patrimonial.

En todo el mundo, se han realizado avances considerables en cuanto a la puesta en valor del patrimonio militar o fortificado: se ha logrado reactivar espacios que se encontraban en ruinas, olvidados, para otorgarles una vida social activa y con compromiso, por ejemplo, en Brasil, Perú, España, Argentina, entre otros. Resalta el caso de Uruguay, donde se ha logrado dar presencia y dinamismo al patrimonio militar que estaba por perderse, pues queda muy poca evidencia física del mismo.

Con esa idea, comenzó este proyecto, mediante el cual se continuará realizando propuestas de reconstrucción virtual, como ha sucedido en el caso del Presidio del Gallo. Se está trabajando en los demás y ya se cuenta con considerables avances en el caso de Cerro Gordo, que quizá pronto sea motivo de publicación editorial.

Tomando en cuenta estas propuestas de reconstrucción virtual es posible comprender mejor los espacios y las actividades que allí se realizaban, así como entender cómo se fue poblando el norte de México a partir de esta estrategia de ocupación militar y civil.

\section{Referencias}

Carrillo Acosta, R. (2013). Ocupación de la Nueva Vizcaya. Presidios en el Camino Real de Tierra Adentro, durante los siglos XVII y XVIII [Tesis de doctorado sin publicar]. Universidad Autónoma de Zacatecas, Zacatecas, México.

Vallebueno Garcinaba, M. (2011). El Camino Real de Tierra Adentro. Travesía histórica y cultural al septentrión novohispano. Durango, México: Gobierno del Estado de Durango.

Guevara Sánchez, A. (2011). Presidio y población indígena en la Nueva Vizcaya. Siglos XVII y XVIII [Tesis de doctorado en historia]. Unidad Michoacana de San Nicolás de Hidalgo, Michoacán, México.

Moorhead, M. (2012). El presidio (3era Ed.). Chihuahua, México: Gobierno del Estado de Chihuahua.

Arnal Simón, L. (1998). El presidio en México en el siglo XVI. Ciudad de México, México: Universidad Nacional Autónoma de México.

Centro INAH Durango. (2005). Documentación de bienes del patrimonio cultural asociados al Camino Real de Tierra Adentro. Durango, México: CONACULTA/INAH.

Carrillo Acosta, R.; \& Castillo Ruiz, F. (julio-diciembre, 2017). Transformación de las fortificaciones en el norte del Camino Real de Tierra Adentro en México: El caso del Presidio de El Pasaje. Devenir, 4(8), 97-122. Lima, Perú: Universidad Nacional de Ingeniería.

Autos sobre la formación del presidio del Cerro Gordo por mandato del conde de Salvatierra, virrey, Pueblo del Tizonazo. (1646, 10 de agosto). Milicias y Guerra, Administración de milicias (Caja 1, expediente 3).

Jiménez, A. (2006). El gran norte de México. Una frontera imperial en la Nueva España (1540 - 1820). Madrid, España: Tébar. 